\title{
TRANSFORMASI KAJIAN KEISLAMAN PADA \\ LEMBAGA DAKWAH KAMPUS (LDK) JUNDULLAH IAIN PALU
}

\author{
Mariam Mariam \\ Syamsuri Syamsuri \\ Mansur Mangasing \\ Institut Agama Islam Negeri Palu \\ Email: syamsuri.palu@yahoo.com
}

\begin{abstract}
:
LDK Jundullah is organization of da'wah (Islamic preaching) in IAIN Palu that has concerned with Islamic studies. Therefore, students and also community can understand Islam as a religion that is able to form a good character. In addition, Islamic studies can be alternative to relieve a boredom for society due to the emergence of new schools in Islam that are in contradicton with the Quran and Sunnah. This organization carry out activities such as organizing seminars, training of preacher, weekly meeting (liqo), two-level training (daurah) for new comers, female Muslim activities, and economic empowerment. The activities done by the activists of LDK Jundullah are focused on good character and exemplary in campus and society.

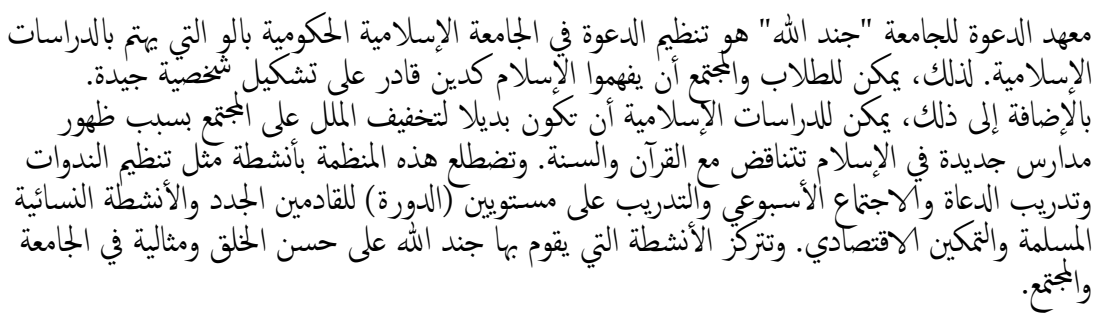

Kata Kunci: Aktivitas, kajian kelslaman, lembaga dakwah kampus 
Mariam, Syamsuri, Adam, Transformasi Kajian Keislaman....

\section{A. Pendahuluan}

Sebagai sebuah petunjuk keselamatan bagi manusia di dunia dan akhirat, dakwah Islam mutlak dilakukan agar Islam menjadi rahmat serta penyejuk bagi kehidupan manusia. Bila kehidupan manusia menjadi baik, maka seluruh kehidupan alam lainnya juga menjadi baik pula. ${ }^{1}$

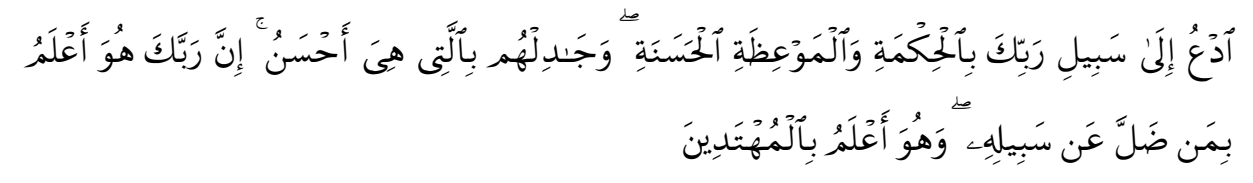

Terjemahnya:

"Serulah (manusia) kepada jalan Tuhan-mu dengan hikmah dan pelajaran yang baik dan bantahlah mereka dengan cara yang baik. Sesungguhnya Tuhanmu Dialah yang lebih mengetahui tentang siapa yang tersesat dari jalan-Nya dan Dialah yang lebih mengetahui orang-orang yang mendapat petunjuk". (QS. An Nahl: $125)^{2}$

Pada hakikatnya kegiatan dakwah merupakan aktivitas untuk mengajak manusia agar berbuat kebaikan dan menurut petunjuk, menyeru mereka berbuat kebajikan dan melarang mereka dari perbuatan mungkar agar mendapat kebahagiaan di dunia dan akhirat.

Di samping itu, dakwah Islam juga dapat dimaknai sebagai usaha dan aktivitas orang beriman dalam mewujudkan ajaran Islam dengan menggunakan sistem dan cara tertentu kedalam kenyataan hidup perorangan, keluarga, kelompok, masyarakat dan Negara merupakan kegiatan yang menyebabkan terbentuknya komunitas dan masyarakat

${ }^{1}$ Moh. Ali Aziz, Ilmu Dakwah, Edisi Revisi, (Cet Ke-II; Kencana, 2009 Jakarta), h. 105.

${ }^{2}$ Departemen Agama RI, Al-Jumatul 'Ali Alqurān dan Terjemahnya, (Bandung: JArt, 2014), h. 421 
muslim serta peradabannya. Tanpa adanya aktifitas dakwah, masyarakat muslim tidak mungkin terbentuk. Oleh karena itu, dakwah merupakan aktifitas yang berfungsi mentransformasikan nilai-nilai Islam sebagai ajaran/doktrin menjadi kenyataan tata masyarakat dan peradabannya yang mendasarkan pada pandangan dunia Islam yang bersumber pada Al quran dan As-Sunnah. Oleh karena itu, dakwah Islam merupakan faktor dinamik dalam membentuk terwujudnya masyarakat yang berkualitas. ${ }^{3}$

Syeikh Ali Mahfuzh menjelaskan "Dakwah dapat memotivasi manusia agar melaksanakan kebaikan dan mengikuti petunjuk, yakni berbuat baik dan mencegah yang mungkar, supaya mereka mendapat kebahagiaan hidup di dunia dan di akhirat". ${ }^{4}$

Dengan perencanaan, penyelenggaraan dakwah dapat berjalan secara lebih terarah dan teratur rapi. Hal ini dapat terjadi dengan pemikiran secara masak mengenai apa yang harus dilaksanakan dan bagaimana cara menjalankan dakwah, maka dapatlah dipertimbangkan kegiatan apa yang harus dilakukan; "Dan hendaklah ada di antara kamu segolongan umat yang menyeru kepada kebajikan, menyuruh kepada yang ma'ruf dan mencegah dari yang munkar merekalah orang-orang yang beruntung". (QS. Ali Imrān: 104) $)^{5}$

Dakwah di dalam Islam merupakan masalah besar yang menyangkut hajat dan kepentingan masyarakat luas. Sebab pada kenyataannya Islam tidak akan berkembang tanpa adanya dakwah

${ }^{3}$ Samsul Munir Amin, Ilmu Dakwah, (Jakarta: Amzah, 2009,h.18

${ }^{4}$ Totok Jumantoro, Psikologi Dakwah dengan Aspek-aspek Kejiwaan yang Qur'ani, (Jakarta: Amzah, 2001), h. 17-18

${ }^{5}$ Departemen Agama RI, Al-Jumatul 'Ali Alqurān dan Terjemahnya, (Bandung: J-Art, 2014), h. 93 
Mariam, Syamsuri, Adam, Transformasi Kajian Keislaman....

Islamiyah yang disebarkan oleh para tokoh-tokoh dakwah, karena dalam kehidupan Rasulullah SAW, amat sarat dengan kegiatan dakwah. Demikian pula yang dikembangkan oleh para sahabat, dan penerusnya.

Dakwah Islam yang dikembangkan oleh Rasulullah pada awalnya adalah mendidik kader-kader dakwah, dimana kader-kader Nabi ini nantinya akan menjadi tokoh-tokoh dakwah yang handal dalam menegakkan kalimat Allah yaitu agama Islam, serta meniru tingkah Rasulullah sebagai suri teladan yang baik. Pendidikan dakwah oleh Rasulullah ini, antara lain dilaksanakan dirumah Al-Arkam Bin Abi Arkam, dimana ditempat ini terkenal sebagai tempat penggodokan para mujahid dakwah yang didik oleh Rasulullah.

Dengan sejumlah kader mujahid dakwah generasi awal ini kemudian Rasul bergerak membangun umat yang berhasil dibangun, yaitu umat dakwah, yang oleh Alquran digambarkan sebagai ummatan wahidatan, umat yang bersatu, dan diakui sebagai khairah ummah. Tahap selanjutnya dengan model khairah ummah kemudian Rasulullah dan para sahabatnya mengembangkan ekspansi dakwah dengan cara mengirimkan ekspedisi-ekspedisi muballigh ke berbagai penjuru dunia, sehingga didalam waktu yang tidak terlalu lama, perjuangan dakwah ini membuahkan eksistensi peradaban Islam.

Dengan penuh kesabaran dan perencanaan yang matang, strategi dakwah yang diperjuangkan oleh Rasulullah dapat berjalan dengan baik dan pada akhirnya memperoleh dukungan dari sebagian besar masyarakat Arab. Dari sini, Islam terus dikembangkan oleh Rasulullah, dan para penerus panji-panji dakwah Islam sehingga Islam berkembang ke seseluruh dunia tidak lain karena adanya aktifitas dakwah. 
Jelaslah bahwa keberadaan dakwah Islamiyah sangat diperlukan Dalam Islam. Dakwah merupakan ujung tombak bagi pengembangan agama Islam. Islam tidak akan berkembang, masyarakat muslim tidak akan terbentuk dibelahan dunia manapun, manakala aktifitas dakwahnya terhenti. Islam dapat berkembang dikarenakan adanya aktifitas dakwah.Di sini tampak jelas nilai penting aktifitas dakwah Islam. ${ }^{6}$

Melalui proses perjalanan yang panjang kegiatan aktivitas dakwah Islam berkembang pesat hingga ke berbagai benua. Dari sejarah perjalanan dakwah Islam tersebut mempengaruhi banyak kalangan mahasiswa muslim khususnya di Indonesia untuk melakukan sebuah forum dan perkumpulan diberbagai tempat dan masjid, hingga mereka melakukan regenerasi kegiatan dakwah di dalamnya. Makin maraknya kegiatan dakwah saat itu, mendorong sejumlah aktivis Islam untuk melembagakan gerakan dakwah di dalam kampus menjadi unit kegiatan mahasiswa yang resmi. Lalu munculah lembaga dakwah kampus tak lama setelah berdiri, lembaga dakwah kampus mulai menjalin hubungan antara sesama lembaga dakwah diberbagai kampus lainnya, dimana lembaga dakwah kampus menerapkan masing-masing strategi dakwahnya untuk terus mempertahankan dan mengembangkan dakwah Islam kedepannya. Jejaring yang dilakukan aktivis lembaga dakwah kampus tersebut menggelar pertemuan dari berbagai lembaga dakwah kampus lainnya dan melahirkan sebuah forum silaturahmi lembaga dakwah kampus yang digelar di malang, hingga kini lembaga dakwah kampus pertumbuhannya

${ }^{6}$ Ibid., h. 20-23 
Mariam, Syamsuri, Adam, Transformasi Kajian Keislaman....

sudah mulai pesat di berbagai kampus di Indonesia, sedikitnya ada kurang lebih 800 lembaga dakwah kampus yang ada di Indonesia. ${ }^{7}$

Berdasarkan uraian latar belakang di atas, maka penulis merumuskan pokok permasalahan yang muncul dalam tulisan ini adalah: Bagaimana transformasi kajian keislaman LDK Jundullah IAIN Palu? Pertanyaan inilah yang akan dikaji dalam tulisan ini.

\section{B. Tinjauan Tentang Dakwah}

Di tinjau dari sudut etimologi atau asal kata (bahasa), Dakwah berasal dari bahasa Arab yang berarti panggilan, ajakan atau seruan.Dalam ilmu tata bahasa Arab, kata Dakwah berbentuk sebagai isim masdar. Kata ini berasal dari kata fi'il (kata kerja) da'a, yad'u, da'watan yang artinya memanggil, mengajak, atau menyeru. ${ }^{8}$ Kata Dakwah sering dijumpai atau dipergunakan dalam ayat Alquran surah ali Imrā (3): 104; "Dan hendaklah ada di antara kamu segolongan umat yang menyeru kepada kebajikan...".

Sedang orang yang melakukan seruan atau ajakan tersebut dikenal dengan "Dai" (orang yang menyeru) dan mubaligh yaitu orang yang berfungsi sebagai komunikator untuk menyampaikan pesan (message) kepada pihak komunikan. ${ }^{10}$

${ }^{7}$ http://yopiekristiyanto.blogspot.com/2013/02/diklat-kader-dakwah kepemimpinan. Html. Diakses tanggal 01 Mei 2016.

${ }^{8}$ Asmudi Syukir, Dasar-dasar Strategi Dakwah Islam, (Surabaya: al-Ikhlas, 1983), h. 17.

${ }^{9}$ Kementerian Agama RI, Alqurān dan Terjemahnya, (Bandung: Fokus Media, 2010), h. 63

${ }^{10} \mathrm{Ibid}$, h. 16. 
Sedangkan pengertian dakwah (secara terminologis) terdapat beberapa definisi sebagai berikut: Menurut M. Arifin;

"Dakwah adalah suatu kegiatan ajakan baik dalam bentuk lisan, tingkah laku dan sebagainya yang dilakukan secara sadar dan berencana dalam usaha mempengaruhi orang lain, baik secara individual maupun secara kelompok, agar timbul dalam dirinya suatu pengertian, kesadaran, sikap penghayatan serta pengamatan kepadanya dengan tanpa adanya unsur-unsur paksaan". ${ }^{11}$

Sahal Mahfudh, (1994), dalam bukunya Nuansa Fiqih Sosial, mendefinisikan; "Dakwah adalah usaha sadar yang disengaja untuk memberikan motifasi kepada orang atau kelompok (biasa disebut kelompok sasaran) yang mengacu kearah tercapainya tujuan. ${ }^{12} \mathrm{M}$. Isa Anshary, (1995), mengartikan "Dakwah Islamiyah yaitu menyampaikan seruan Islam, mengajak dan memanggil umat manusia, agar menerima dan mempercayai keyakinan dan pandangan Islam". ${ }^{13}$

Dari definisi-definisi tersebut diatas dapat diketahui bahwa dakwah itu merupakan aktifitas yang mempunyai tujuan tertentu yaitu mengajak manusia untuk melaksanakan kegiatan amal Makruf Nahi Mungkar adapun unsur-unsur dakwah meliputi materi, subyek dan obyek dakwah, metode dan media dakwah.

Secara garis besar ada dua pola pengertian yang selama ini hidup dalam pengertian dakwah.Pertama, bahwa diberi pengertian sebagai semua usaha untuk merealisir ajaran Islam dalam semua segi kehidupan manusia.Pola pengertian yang kedua sebagai semua usaha untuk

\footnotetext{
${ }^{11}$ Arifin, Psikologi Dakwah Suatu Pengantar Studi (Bumi Aksara), h. 31

12 Sahal Mahfudh, Nuansa Fiqih Sosial, (Cet I, Yogyakarta: LKIS, 1994), h. 101.

${ }^{13}$ Isa Anshory, Mujahid Dakwah, Pembimbing Mubaligh Islam, (Cet V; Bandung: Diponegoro, 1995), h. 17.
} 
Mariam, Syamsuri, Adam, Transformasi Kajian Keislaman....

menyebarluaskan Islam dan merealisir ajarannya di tengah masyarakat dan kehidupannya. Kata menyebarluaskan Islam berarti fleksibel (mudah dan cepat menyesuaikan diri), karena mengandung unsur penyebaran, perluasan, pengembangan dan penyiaran Islam sesuai dengan pengertian dari kata al-da' watu al-Islam atau al-da'watu ila al-Islam. ${ }^{14}$

Dalam pandangan yusuf Qardawi yang dimaksud dakwah yaitu dijalan Allah swt. Artinya, dakwah itu mengajak menusia menganut ajaran Allah (Agama Allah) menuruti petunjuk dan peraturannya, seraya menganggap hak yang dinyatakan oleh Allah, umat manusia dengan hikmat kebijaksanaan untuk mengikuti petunjuk Allah swt dan Rasulnya. ${ }^{15}$ Melakukan amal makruf nahi mungkar dan berjihad demi menuju jalan-nya.dengan kata lain dakwah ialah mengajak manusia menjadi muslim yang sejati. Kerena seorang Dai dituntut memiliki wawasan yang luas dan berkemampuan tinggi untuk menyalakan api Islam.

Untuk itu sependapat dengan bukunya Abdul Halim Hamid dalam menegakkan amal makruf nahi mungkar ada tiga yang dijadikan pegangan oleh seorang Dai yakni: Ilmu, kelamah lembutan dan kesabaran.

Semakin jelas bahwa aktifitas dakwah yang dilakukan oleh seorang Dai memerlukan kesiapan-kesiapan, agar dapat tercapai semua yang sudah menjadi kewajiban sorang muslim, untuk menuju kebahagiaan dunia dan akhirat.

${ }^{14}$ Dzikron Abdullah, Metodologi Da'wah (Semarang: Fakultas Dakwah IAIN Walisongo Semarang, 1987), h. 7.

${ }^{15}$ Hamzah Ya'qub, Publistik Islam, Tekhnik Da'wah dan Leadership (Cet II, Bandung: Diponegoro, 1981), h. 18. 
Sasaran dakwah (mad'u, comunican, audiens). Objek dakwah itu masyarakat penerima dakwah, individu maupun kelompok sebagai objek dakwah, memiliki strata dan tingkatan yang berbeda. Dalam hal ini seorang Dai dalam aktivitas dakwahnya, hendak memahami karakter dan siapa yang akan di ajak bicara atau siapa yang menerima pesan-pesan dakwahnya, perlu mengetahui klasifikasi dan karakter objek dakwah hal ini penting agar pesan-pesan dakwah di terima dengan baik oleh mad'u.

Dengan mengetahui karakter dan kepribadian mad'u sebagai penerima dakwah, maka dakwah akan lebih terarah karena tidak di sampaikan serampangan tetapi mengarah kepada profesionalisme. Maka mad'u sebagai penerima dakwah akan dengan mudah menerima pesanpesan dakwah yang telah di sampaikan oleh subjek. Karena baik materi, metode, maupun media yang di gunakan dalam berdakwah tepat sesuai kondisi mad'u sebagai subjek dakwah.

\section{Fenomena Dakwah Kampus}

Menelisik fenomena Dakwah didunia kampus, kadang setiap pribadi memiliki karakter dan keunikan masing-masing, menarik untuk diamati.Kadang kala dikampus, ada ikhwan dan akhwat yang lebih suka dan senang dilini dakwi' saja, ada pula ikhwan dan akhwat yang merasa nyaman dilini syiasi dan adapula ikhwan dan akhwat yang cenderung hanya fokus untuk kuliah dan akademik saja, yakni dapat kita kelompokkan ikhwan dan akhwat pada lini ilmi'.Namun, adapula ikhwan dan akhwat yang dikampus tidak berpartisipasi sekali kedalam tiga lini tersebut.Sebagian dari ikhwan dan akhwat ini hanya menikmati saja dan tidak memiliki banyak peran dan andil di dakwah kampus.Tapi, tetapi saja mereka mencintai forum ini, mereka mencintai Islam dan mereka 
Mariam, Syamsuri, Adam, Transformasi Kajian Keislaman....

mencintai dakwah. Hanya saja pemahaman akan Dakwah yang belum menyeluruh mereka pahami. ${ }^{16}$

Di negeri kita Indonesia, proses-proses perubahan tidak lepas dari peran kaum muda terutama kaum muda terdidik atau mahasiswa.Bahkan perannya makin menonjoli erah pergerakan kemerdekaan.Kaum muda terpelajar melakukan konsolidasi, pengkaderan advokasi rakyat di hadapan kolonialis belanda, hingga bangsa ini merebut kemerdekaan.Awal kemerdekaan bangsa ini di penuhi pemikiran dan geliat pergerakan kaum mudah terpelajar (mahasiswa).

Secara sosial kampus merupakan lingkungan kaum muda terpelajar (mahasiswa) yang senantiasa di asah kemampuan berfikirnya sehingga yang di kembangkan kepada mahasiswa adalah kemampuan nalar logika, nalar kritis, rasionalitas dan tentunya kesadaran dalam kehidupan bermasyarakat berbangsa dan bernegara. Sehingga ketika kampus/mahasiswa di injeksi dengan sebuah gerakan Dakwah, maka pada dasarnya ada transformasi nila-nilai ilahiah kepada mahasiswa sehingga tumbuh pemamahaman dan kesadaran akan posisi dan tanggung jawabnya dalam kehidupan di muka bumi (khalifatu fil ardhi).

Secara umum dakwah kampus menjadi titik temu antara dunia kampus yang liberal (material) nilai-nilai dakwah ilahiyah dan semangat darah mudah (psikologi).

Pada situasi yang saling bersinergi, dakwah kampus akan menjadi energi perubahan yang besar (agent of change). Karena kemampuan nalar kritis di dasari oleh visi ilahiyah dan tanggung jawab kepemimpinan serta di dorong oleh semangat segera bertindak melakukan

\footnotetext{
${ }^{16}$ http:/adhiecupu91.blogspot.com/2014/11/fenomenadakwahkampus.htm\#pages /2. diakses pada 15 Mei 2016.
} 
perbaikan.Tantangan berat bagi perkembangan dakwah kampus datang dari arus kapitalisme dan liberalisme yang telah menyentuh berbagai sendi kehidupan ummat manusia. Hal ini paling dirasakan pada aspek pendidikan tinggi yang terus di dorong untuk melakukan liberalisasi. Dampaknya adalah makin mahalnya biaya pendidikan dan makin ketatnya jadwal akademi mahasiswa. Hal ini menimbulkan dilema bagi kalangan mahasiswa antara dunia aktivis dan akademi. ${ }^{17}$

Aspek yang lain adalah makin menguatnya dunia konsumerisme di kalangan masyarakat. Kapitalisme yang pada dasarnya mendorong masyarakat berprilaku konsumtif, pada saatnya ini telah mampu mendorong aktifitas dakwah menjadi kebutuhan yang sifatnya konsumtif. Artinya kajian-kajian Islam lebih menonjolkan sosok (distereotipkan selebritis) dari pada subtansi nilai. Situasi ini sering menimbulkan perbenturan antara nilai-nilai Islam sendiri dengan sosok yang telah terkapitalisasi. Efeknya adalah pada pembangunan citra Islam di kulturasi nilai-nilai Islam. Untuk itu, aktualisasi peran dakwah kampus sebagai problem solver harus di barengi dengan kejelian memandang fenomena berduyun-duyunnya masyarakat mengikuti kajian masal menunjukan kehidupan masyarakat cenderung Islami. Karena pada satu sisi dunia mall dan hipermartket juga makin di gandrungi, Artinya ada fenomena yang kontradiktif. Jika dakwah kampus hanya ingin meramaikan masjid yang ada di kampusnya maka cukuplah gerakan ini berada di ruangan kampus saja tapi pasti akan di pertanyakan komitmen akan kepedulian atas degradasi kemanusiaan yang sedang melanda bangsa ini. Jika dakwah kampus ingin memasuki peran penguatan masyarakat, maka dakwah

\footnotetext{
${ }^{17} \mathrm{http} /$ muslimahpejuang. wordpress.com/2011/01/10/ problematika dakwah kampus dan solusinya. Di akses pada 10 Mei 2016 jam 9.
} 
Mariam, Syamsuri, Adam, Transformasi Kajian Keislaman....

kampus harus masuk keruang-ruang sosial kultural masyarakat. Tapi jika dakwah kampus akan mengambil peran gerakan politik nilai di hadapan penyelenggara negara, maka penting kiranya membangun unifikasi dakwah kampus nasional secara definitif. Hal ini juga penting ketika dakwah kampus akan merambah ke ruang internasional. ${ }^{18}$

Dakwah kampus merupakan posisi yang paling strategis mengawal perubahan bahkan dakwah kampus dianggap tiang dan puncak aktifitas dari dakwah yang hasil paling progresif. Hal ini dapat kita lihat dalam shiroh bahwa generasi awal yang menerima dakwah adalah para pemuda, dengan adanya dakwah kampus, di harapkan dapat memperbanyak pendukung showatul Islam (kebangkitan Islam). Dakwah kampus adalah untuk membentuk bi'ah (lingkungan) Islamiyah di kampus, dengan begitu arus jahiliyah dalam kampus dapat di redam, bahkan di hancurkan serta menumbuhkan dan mengokohkan tayarul Islamiyah di kampus. Dewasa ini bangsa Indonesia tengah di landa berbagai macam krisis yang berkepanjangan dan tak kunjung usai, mulai dari krisis moralitas bangsa hingga problematika kenegaraan. Dakwah kampus sebagai sebuah entitas vital dan strategis.Indonesia hendaknya mampu menjadi problem solver bagi setiap permasalahan yang ada atau setidakanya bisa memberikan kontribusi nyata bagi setiap upaya perubahan kearah yang lebih baik.Mahasiswa sebagai agen of change yang memiliki kekuatan idealitas serta kejernihan berfikir, hendaknya mampu melandaskan dirinya pada keluhuran akhlak serta budi pekerti yang mulia. Dalam konteks yang seperti inilah, maka dakwah kampus memiliki peran yang sangat penting sebagai motor penggerak bagi

${ }^{18}$ Ibid. h. 30. 
aktifitas dakwah di kampus. Aktifitas yang senantiasa mengajak manusia untuk beramar ma'ruf nahyi munkar, memberikan pemahaman kepada setiap manusia akan posisi dirinya sebagai Abdullah dan khalifa fil ardh. ${ }^{19}$

\section{Lembaga Dakwah Kampus}

Menghadapi persoalan yang demikian besar dan luasnya tidak akan mungkin di selesaikan dengan baik, jika hanya di hadapi oleh seorang mubaligh atau dai saja. Jadi pada prinsip semua masalah itu harus di hadapi secara bersama-sama, kolektif, kerja sama, gotong royong oleh ahlinya masing-massing dan orang yang mempunyai hubunngan dalam masalah dakwah Islam. Kerja samayang demikian ini barulah dapat terwujud apabila di bina dalam suatu ikatan yang mengatur langka-langka yang seragam. Kerja sama gotong royong ini pada hakikatnya adalah suatu organisasi .

Organisasi dalam kamus besar bahasa indonesia, ialah kesatuan yang terdiri di atas bagian di dalam perkumpulan untuk tujuan tertentu, selain itu organisasi juga dapat di defenisikan sebagai kelompok kerjasama untuk mencapai tujuan bersama. ${ }^{20}$ Sedangkan organisasi menurut Schein adalah suatu kordinasi rasional sejumlah orang untuk mencapai suatu beberapa tujuan umum melalui beberapa pembagian pekerjaan dan fungsi dari hirarki otokritas dan tangung jawab. L. Gibson mengatakan organisasi adalah etentitas yang memungkinkan masyarakat 2007) h. 56

${ }^{19}$ Gamais ITB. Risalah Manajemen Dakwah Kampus, ( Bandung: Gamais Press,

${ }^{20}$ Departemen Pendidikan Dan Kebudayaan, kamus Besar Bahasa Indonesia, (Balai Pustaka), h. 630 
Mariam, Syamsuri, Adam, Transformasi Kajian Keislaman....

mencapai hasil-hasil tertentu, yang tidak mungkin di lakukakan individuindividu yang bertindak sendiri. ${ }^{21}$

Organisasi LDK Jundullah adalah sebuah organisasi kemahasiswaan intra kampus yang terdapat di tiap-tiap perguruan tinggi di Indonesia.Organisasi ini berpedoman pada dakwah sebagai landasan amal sebuah lembaga yang legal, formal dan wajar. Ada pedoman asasi yakni Alqurān dan sunnah, ada pedoman oprasional yakni AD/ART, GBHD (garis-garis besar haluan dakwah)/ GBHK dan rencana strategis. AD/ART memiliki fungsi tambahan yakni dalam sudut pandang legalitas $\mathrm{LDK}^{22}$

Lembaga Dakwah Kampus merupakan sumber rekruitmen generasi Islam intelektual mandiri yang secara tidak langsung mendukung suksesnya perkembangan Islam, ilmu pengetahuan, dan teknologi. Merupakan sarana kordinasi Lembaga Dakwah Kampus yang bermanhaj Ahlusunnah Wal Jamaah dan merupakan.Tonggak pergerakan dakwah mahasiswa di seluruh kampus Indonesia. ${ }^{23}$

\section{E. Lembaga Dakwah Kampus Jundullah IAIN Palu}

Tulisan ini di laksanakan di organisasi LDK Jundullah IAIN Palu Jl. Diponegoro keluran Lere Kec. Palu Barat. Lembaga Dakwah Kampus (LDK) Jundullah IAIN Palu Lahir Pada Tahun 2002, seminggu setelah OSTAK berakhir ada beberapa ADK (Aktifis Dakwah Kampus) yang

${ }^{21}$ J. Winandi, Teori Organisasi Dan Pengorganisasian, (Jakarta: PT. Raja Grafindo Persada, 2006), h. 13.

${ }^{22}$ Dimas, Risalah Manejemen Dakwah Kampus, (Cet. 1: lampung: Gamais Press, 2007), h. 40.

${ }^{23}$ Wahyudin, Pergerakan Dakwah Kampus di Indonesia (Cet. 1; Yogyakarta: AlAmin Press, 1992), h. 15. 
mendapat Undangan dari Muzakirah dan Ufil Damayanti sebagai inisiator untuk mengaktifkan kembali Taman Pengajian (TP) Al-Jundullah yang sudah tidak aktif lagi. Kemudian dari hasil rapat tersebut disepakati bahwa nama TP di ganti menjadi LDK (Lembaga Dakwah Kampus) Al-Jundullah yang kemudian juga berganti menjadi Jundullah berdasarkan masukan Ustaz Dr. Abdul Basyir Marjudo, M.H.I. ${ }^{24}$

Setelah berganti nama dari TP atau taman pengajian menjadi LDK Jundullah IAIN Palu, Organisasi ini belum langsung mendapatkan SK dari Kampus IAIN Palu yang dulunya masih di kenal dengan sebutan Sekolah Tinggi Agama Islam Negeri (STAIN) Palu, akan tetapi setelah berjalan satu tahun seluruh program-program kerja Organisasi Lembaga Dakwah Baru Mendapatkan SK dari Kampus STAIN pada Tahun 2003. ${ }^{25}$

Bulan pertama, seluruh pengurus konsen pada persiapan legalitas LDK sebagai UKM di lingkungan STAIN. dan pada Kongres Mahasiswa di tahun 2003, LDK dinyatakan sah sebagai salah satu UKM di Lingkungan STAIN. Namun beberapa minggu kemudian LDK oleh BLM di bekukan seluruh aktifitasnya sambil menunggu SK dari Ketua STAIN keluar. ${ }^{26}$

Manhaj Organisasi LDK Jundullah IAIN Palu adalah ahlu sunna wal jamaah hal ini yang menyebabkan banyaknya anggota yang ikut bergabung dalam organisasi LDK, selain itu para anggota yang ikut bergabung dalam LDK Jundullah IAIN Palu berasal dari beberapa organisasi lainnya yaitu organisasi di dalam kampus dari LPM, Sema, Dema, dan HMJ kemudian ada juga dari organisasi luar kampus Wahda,

\footnotetext{
${ }^{24}$ Arsip dokumen Lembaga Dakwah Kampus Jundullah IAIN Palu. h. 2.

${ }^{25}$ Mardatillah Wawancara. Di kampus IAIN PaluPada tanggal 03 Juli 2016.

${ }^{26}$ Ibid. h. 15.
} 
Mariam, Syamsuri, Adam, Transformasi Kajian Keislaman....

KAMMI, HMI, dan HTI. karena slogan mantan Ketua LDK Jundullah Muammar Zuhdi Arsalan "Berpelangi Dengan Cinta" jadi meskipun mereka berbeda tetapi mereka di satukan dalam dakwah.

\section{Landasan dibentuknya Lembaga Dakwah Kampus}

Ada beberapa alasan yang menjadi dasar dibentuknya organisasi lembaga dakwah kampus jundullah yaitu:

a. Rasulullah SAW memberikan perhatian yang besar kepada para pemuda

b. Pentingnya dukungan para pemuda sebagai prasyarat tegaknya suatu pemikiran atau pergerakan

c. Kekhasan mahasiswa Indonesia

d. Pelajaran dari sejarah

e. Masalah regenerasi, pewarisan nilai dan pengalaman adalah bagian penting untuk diperhatikan

f. Masa reformasi telah membawa kampus menjadi medan kompetisi antar pergerakan yang lebih terbuka

$\mathrm{g}$. Fenomena melemahnya proses tarbiyah di kampus-kampus baik secara kwalitas maupun kwantitasnya

h. Perlunya sinkronisasi, untuk optimalisasi dakwah

i. Perlunya disiplin penerapan manhaj dalam pengelolaan tarbiyah termasuk di kampus. ${ }^{27}$

Landasan Dibentuknya Organisasi lembaga Dakwah kampus Jundullah menurut syar'i diambil dari beberapa ayat Alqurān yaitu:

a. QS An Nahl (16): $125^{28}$;

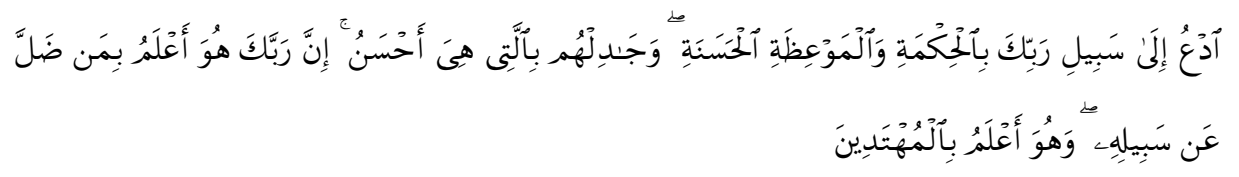

\section{${ }^{27}$ Ibid. h. 16}

${ }^{28}$ Departemen Agama RI, Al-Jumatul 'Ali Al-quran dan terjemahnya (Bandung: CV Penerbit J-Art, 2014), h. 421. 
Terjemahnya:

"Serulah (manusia) kepada jalan Tuhanmu dengan hikmah dan pelajaran yang baik, dan bantahlah mereka dengan cara yang baik".

b. QS. at Taubah (5): $122^{29}$;

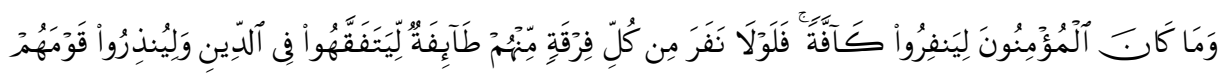

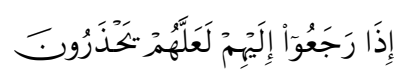

Terjemahnya:

"Tidak sepatutnya bagi mukminin itu pergi semuanya (ke medan perang).mengapa tidak pergi dari tiap-tiap golongan di antara mereka beberapa orang untuk memperdalam pengetahuan mereka tentang agama dan untuk memberi peringatan kepada kaumnya apabila mereka telah kembali kepadanya, supaya mereka itu dapat menjaga dirinya".

c. Q.S. Mujādalah (58): 11;

"Berdirilah kamu", Maka berdirilah, niscaya Allah akan meninggikan orang-orang yang beriman di antaramu dan orangorang yang diberi ilmu pengetahuan beberapa derajat". ${ }^{30}$

d. Q.S. al-Māidah (5): 2;

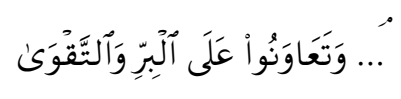

Terjemahnya:

"Dan tolong-menolonglah dalam kebajikan dan taqwa". ${ }^{31}$

\footnotetext{
${ }^{29}$ Ibid. h. 301.

${ }^{30} \mathrm{Ibid}$. h. 910.

${ }^{31}$ Ibid. h. 157.
} 
a. Q.S. al-Kahfi (18): 13-14;

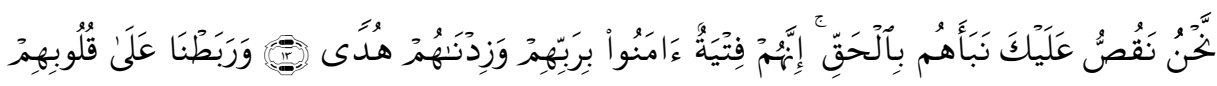

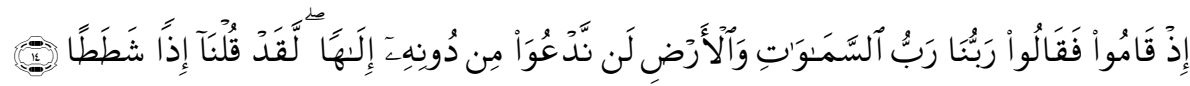

Terjemahnya:

"Sesungguhnya mereka itu adalah pemuda-pemuda yang beriman kepada Tuhan mereka dan Kami tambahkan kepada mereka petunjuk; dan Kami telah meneguhkan hati mereka di waktu mereka berdiri (dihadapan penguasa)".(Al Kahfi:13-14). ${ }^{32}$

b. Q.S. al-Qașaș (28): 6;

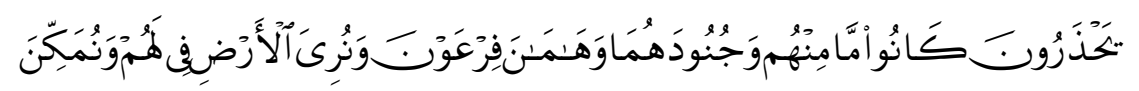

Terjemahnya:

"Dan Kami hendak memberikan karunia kepada orang-orang yang tertindas di bumi, dan hendak menjadikan mereka pemimpin dan menjadikan mereka orang-orang yang mewarisi (bumi), dan akan Kami teguhkan kedudukan mereka di muka bumi dan akan Kami perlihatkan kepada Fir'aun, Haman dan balatentaranya apa yang selalu mereka khawatirkan dari mereka itu".33

Tidak hanya menurut Alqurān, pembentukan organisasi lembaga dakwah kampus juga sesuai Landasan As Sunnah yaitu:

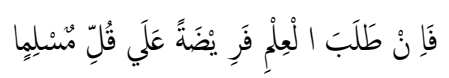

Artinya:

"Menuntut ilmu adalah kewajiban bagi setiap muslim". (HR Ibnu Majah). ${ }^{34}$

${ }^{32}$ Ibid. h. 444.

${ }^{33}$ Ibid. h. 609.

${ }^{34}$ Nasiruddin Al-Albani. Ringkasan Shahih Bukhari. (Cet. I;Jakarta: Gema Insani, 2003), h. 52. 
Dalam hadis lain disebutkan;

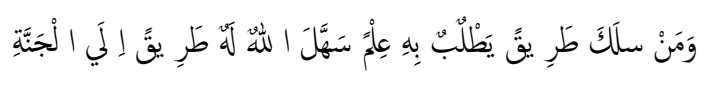

Artinya:

"Barangsiapa yang menempuh jalan untuk mencari ilmu, maka Allah akan memudahkan baginya jalan menuju surga" (HR Muslim). ${ }^{35}$

\section{Kepengurusan Lembaga Dakwah Kampus Jundullah IAIN Palu}

Pengurus Lembaga Dakwah Kampus Jundullah dari tahun 20022004 ketahun yang disepakati pengurusnya yaitu Zaid Yalidjama sebagai ketua dan Moh. Arifin sebagai sekertaris kemudian di gantikan oleh Rizal dan jabatan seterusnya di gantikan oleh Muh.Sukron. Berikut nama-nama ketua Lembaga Dakwah Kampus (LDK) IAIN Palu yang pernah menjabat dari Tahun 2002-2015.
a. 2002: Ketua LDK adalah Zaid Yalidjama
b. 2003: Ketua LDK adalah Rizal
c. 2004: Ketua LDK adalah Muh. Syukron
d. 2005: Ketua LDK adalah Abd. Manan
e. 2006: Ketua LDK adalah Naufal Abd. Rahman
f. 2007 : Ketua LDK adalah Swandi
g. 2008 : Ketua LDK adalah Rudi
h. 2009: Ketua LDK adalah Sufiana
i. 2010: Ketua LDK adalah Kaharuddin
j. 2011: Ketua LDK adalah Muh. Amin
k. 2012: Ketua LDK adalah Donofan

${ }^{35} \mathrm{Ibid}$, h. 51. 
Mariam, Syamsuri, Adam, Transformasi Kajian Keislaman....

1. 2013: Ketua LDK adalah Mufriandi

m. 2014: Ketua LDK adalah Ahmad Khafidil

n. 2015: Ketua LDK adalah Mu'ammar Z.A

o. 2016: Ketua LDK adalah Kaharudin

Dari perjalanan kepengurusan, LDK Jundullah memiliki catatan yang patut dibanggakan yakni pada tahun 2006-2008: LDK di amanahi menjadi PUSKOMDA (Pusat Komunikasi LDK se-Sulawesi diantaranya Sulut, Sulteng dan Gorontalo) ketua Tim: Rizal dan 2010-2012: LDK kembali di amanahi menjadi PUSKOMDA (Pusat Komunikasi LDK seSulawesi (Sulteng dan Sulawesi Utara/Gorontalo), ketua Tim: 2010: Kaharudin dan 2011: Muh. Amin. Sejak tahun 2003-2012 LDK aktif mengikuti kegiatan silaturahim LDK baik regional se-sulawesi maupun nasional se-Indonesia. ${ }^{36}$

3. Visi dan misi Organisasi Lembaga Dakwah Kampus IAIN Palu

Visi:

"Menjadi wadah pengembangan mahasiswa untuk membentuk kader yang berkarakter Islami (sesuai dengan manhaj AhlulSunnahWal Jamaah) dan memiliki kemampuan sebagai mujahid, mujtahid, dan muwahhid demi terwujudnya kampus IAIN yang madani" ${ }^{37}$

Misi:

a. Melakukan pembinaan dan pengembangan potensi mahasiswa.

b. Menciptakan kader yang produktif, sehingga dapat menebar manfaat bagi masyarakat kampus dan masyarakat luas.

c. Menjadi wadah pemersatu umat.

d. Memberikan pelayanan sosial baik intra maupun ekstra.

${ }^{36}$ Arsip dokumen Lembaga Dakwah Kampus Jundullah IAIN Palu. h. 19.

${ }^{37}$ Ibid. 
$\Delta$ L-nish $3 \vec{\Delta}$ H, Volume 13 Nomor 2, Juli-Desember 2017: 367-400

e. Menjadi penggerak utama dalam dakwah AhlulSunnahWal Jamaah.

f. Membantu tercapainya visi dan misi kampus IAIN Palu. ${ }^{38}$

\section{F. Transformasi Kajian Keislaman LDK Jundullah IAIN Palu}

1. Kegiatan Kajian Berdasarkan Program Organisasi

Seluruh aktivitas-aktivitas suatu organisasi dapat dilihat dari program kerjanya begitu pula halnya dengan LDK Jundullah IAIN Palu kita dapat melihat aktifitasnya melalui program kerjanya yang terstruktur dengan baik yaitu sebagai berikut:

a. Departemen dakwah, melakukan seminar-seminar dan membuat pelatihan dai-daiyah.

b. Departemen kadernisasi, untuk mengontrol kader dan membuat program liqo atau mentoring tiap minggu,kemudian ada daura aktifis dakwah kampus satu, itu gerbang masuk LDK dan daura aktifis kampus dua adalah jenjang pendidikan LDK.

c. Departemen kemuslimahan, ini khusus untuk muslimah yaitu mengadakan daura maratu saliha, seminar kemuslimahan, seminar inspiratif, kajian-kajian kemuslimahan.

d. Bidang pemberdayaan ekonomi, melakukan pelatihan kepada para kader LDK dalam berniaga atau berwirausaha. ${ }^{39}$

Masa depan dakwah tergantung pada para penganjur dakwah itu sendiri dalam menerapkan strategi bagaimana melakukan aktivitas dakwah kepada mahasiswa dan masyarakat umum. Untuk menghadapi era dakwah ke depan, ada tiga hal utama yang harus di lakukan:

a. Pembinaan kader harus dilakukan dengan baik, harus di tanamkan keimanan yang mendalam, pemahaman yang juga baik dan cermat tentang keIslaman, lingkungan, konsep-konsep apa saja yang perluh di ketahui dan sebagainya. Kemudian mempunyai amal berkesinambungan dan keterikatan dalam tim kerja yang baik.

$$
\begin{aligned}
& { }^{38} \text { Ibid. } \\
& { }^{39} \text { Ibid. }
\end{aligned}
$$


Mariam, Syamsuri, Adam, Transformasi Kajian Keislaman....

Pembinaan kader ini tidak dapat di tawar-tawar, karena mereka para dai mempunyai tugas qiyadah al-ummah (mempimpin umat), menerapi dan mengobati penyakit masyarakat.

b. Pemerataan dakwah kemasyarakat dan pertumbuhan basis-basis sosial. Apa saja yang dapat menyentuh masyarakat akan berhadapan dengan kekuatan masyarakat. Basis sosial tadi akan menopang para dai dengan simpati, dukungan, dan pengorbanannya, minimal mereka memahami secara umum garis perjalanan dakwah dan arahnya,mereka tahu kader-kader dakwah mempunyai cita-cita dan tujuan dakwah yang baik.Terbentuknya basis sosial, akan menjadi teman utama bagi para kader dakwah nantinya sebab kader-kader itu sendiri di besarkan dari mereka dan harus kembali kepada mereka.Tidak adanya basis sosial ini menyebabkan masalah besar, yaitu banyak gagasan yang tidak di pahami masyarakat, dan sebaliknya banyak masyarakat yang justru mendukung sesuatu yang tidak patut di dukung hanya karena simbol-simbol, pengaruhpengaruh, opini-opini yang berhasil di buat oleh kelompok yang ingin memanipulasi, memanfaatkan, dan mengeksploitasi suara masyarakat.

c. Berjalannya proses percetakan dan penyebaran opini, apa yang di sebut siyara ila al-amal al-Islami. Suatu pembentukan opini yang Islami di arahkan tepat kepada dengan penerimaan dengan sadar akan institusi umat sebab umat ini akan menjadi wacana "kata" belum menjadi sense bagi masyarakat. Dakwah harus di arahkan pada bagaimana mengenal dakwah dan dakwah memahami umat, kemauan untuk saling memahami (tafahum al-ummat al-Islamiah). Bahkan tidak hanya memahami tetapi juga taqabul (menerima)institusinya. 
Walaupun intitusi belum terbangun, tetapi keberadaan apa yang di sebut umat itu mereka pahami. ${ }^{40}$

Penerapan strategi dakwah yang sesuai dengan kondisi mad'u sebagai objek dakwah, akan menghasilkan dakwah yang tepat. Di terima oleh masyarakat sebagai objek dakwah, para wali songoh di jawa misalnya. Karena berdakwah sifatnya kompleks dan multidimensi maka di perlukan pengamatan yang jeli oleh pelaku dakwah untuk dapat menerapkan strategi yang sesuai dengan kondisi mad'u. Dengan demikian aktualisasi dan elaborasi nilai-nilai Islam ke dalam masyarakat akan berhasil dengan baik. ${ }^{41}$

Mardatillah mengatakan bahwa strategi dakwah LDK Jundullah IAIN Palu yaitu:

"Tarbiya Wal Islamiyah mendidik atau membimbing mengenai keIslaman melalui pengkaderan LDK, dan mengadakan kajiankajian keIslaman baik secara face to face (tatap muka) dan lewat media sosial seperti facebook, watshap,instagram dan pusat komunikasi daerah yang di sebut dengan forum silaturahmi lembaga dakwah kampus (FS LDK) yang khusus untuk mengkodinir Lembaga Dakwah Kampus Yang ada di daerah-daerah,organisasi Lembaga Dakwah Kampus lebih banyak menerima informasi dari FS LDK tersebut karena adanya humas dan jaringan yang memberikan informasi-informasi seputar dunia Islam dan ada jaringan muslimah daerah (Jarmus), dan komisi ke-eldekaan”.

Dari beberapa jaringan yang ada di media internet itulah organisasi LDK IAIN Palu mengakses beberapa informasi mengenai

${ }^{40}$ Rahmat Abdullah, Dakwah Masyarakat Fokus Dakwah Di Era Baru, (Cet.I; Jakarta: Penerbit Izzah Press, 2001), h. 22-24

${ }^{41}$ Ibid, h. 110. 
Mariam, Syamsuri, Adam, Transformasi Kajian Keislaman....

informasi-informasi seputar keIslaman seperti kejadian di Negara-negara tetangga yaitu di antaranya Alepo, Swedia dan Pakistan. ${ }^{42}$

Aktivis LDK juga melakukan pertemuan-pertemuan rutin yang sudah dijadwalkan dengan saling bertukar pendapat mengenai informasi yang didapat dari bangku perkuliahan, yakni dengan meningkatkan pemahaman serta wawasan tentang gerakan Lembaga Dakwah Kampus kedepan yaitu dengan melakukan Tranformasi kajian keIslman yang sesuai dengan perkembangan zaman.

Zul Fadli Rais mengemukakan, ada 2 metode dakwah yang di gunakan oleh LDK Jundullah IAIN Palu Yaitu:

1. Metode dakwah dalam tatanan internal

Dalam berdakwah organisasi Lembaga Dakwah Kampus Jundullah IAIN Palu yaitu lebih mencontoh cara dakwah Rasulullah SAW. Yaitu ketika Rasulullah SAW berdakwah di Mekah selama 13 tahun beliau menggunakan sistem tarbiyyah atau pembinaan karena ummat Islam yang terdahulu lebih di tekankan adalah aqidahnya, sama dengan apa yang di lakukan oleh organisasi Lembaga Dakwah Kampus (LDK) Jundullah IAIN Palu melakukan pembinaan dan pembinaan ini juga bukan hanya khusus kader LDK tetapi untuk yang ingin merubah dirinya menjadi yang lebih baik, maka LDK juga merekrut orang-orang dalam Halaqoh (pembinaan) ini sebagaimana yang di lakukan oleh rasullullah saw, misalnya di rumah Arkam bin Abil Arkam mengumpulkan para sahabat-sahabat di rumahnya, di situlah Rasullullah saw mengadakan pembinaan, itulah contoh dakwah Rasulullah SAW yang di terapkan oleh Lembaga Dakwah Kampus (LDK) Jundullah IAIN Palu.

2. Metode dakwah untuk umum (eksternal)

Adapun dakwah untuk umum yaitu melalui seminar-seminar dan melalui teknologi yang ada,lembaga dakwah kampus memanfaatkan media sosial karena di zaman sekarang hampir tidak ada orang yang tidak menggunakan media sosial jadi untuk

${ }^{42}$ Mardaatillah, Wawancara. Sekretariat LDK Jundullah IAIN Palu pada tangal 03 Juni 2016. 


\section{$\Delta L-n i s h 3 \bar{d} h$, Volume 13 Nomor 2, Juli-Desember 2017: 367-400}

penggunaan dakwah melalui media sosial ini sangat efektif,karena orang-orang yang membaca terkadang akan tersadar karena katakata atau pesan-pesan yang di sampaikan melalui media sosial tersebut. ${ }^{43}$

Media dakwah di zaman Rasullullah SAW. Dan para sahabat sangat terbatas, yakni berkisar pada dakwah qauliyah bi al-lisan dan dakwah fi'liyah bi al-uswah, di tambah dengan penggunaan media surat (rasail), yang sangat terbatas. Satu abad kemudian, dakwah menggunakan media dakwah menggunakan media, yaitu qashash (tukang cerita) dan muallafat (karangan tertulis) di perkenalkan.Media yang disebut terakhir ini berkembang cukup pesat dan dapat bertahan sampai saat ini. Pada abad ke 14 hijriah, kita menyaksikan perkembangan di bidang ilmu pengetahuan dan teknologi yang sangat pesat.Di samping pengaruh-pengaruhnya negatif terhadap dakwah.dalam rangka inilah dakwah dengan menggunakan media-media baru seperti surat kabar, majalah, cerpen, cerita bergambar, piringan hitam, kaset, film, radio, televisi, lukisan, stiker, iklan, pementasan di arena pertunjukan, puisi, nyanyian, musik, dan media seni lainnya, dapat mendorong dan membantu para pelaku dakwah dalam menjalankan tugasnya. ${ }^{44}$

Di era reformasi canggih seperti sekarang ini, tidak mungkin dakwah masih hanya menggunakan pengajian di mushallah yang hanya di ikuti oleh mereka yang hadir disana.Penggunaan media-media komunikasi modern adalah sebuah keniscayaan yang harus di

${ }^{43}$ Zul Fadli Rais, Ketua Kadernisasi, Wawancara, di Kampus IAIN Palu pada tanggal 03 juli 2016 .

${ }^{44}$ Ali Yafie, Teologi Sosial Telaah Kritis Persoalan Agama Dan Kemanusiaan, (Yogyakarta: LKPSM, 1997), h. 91-92. 
Mariam, Syamsuri, Adam, Transformasi Kajian Keislaman....

manfaatkan keberadaannya untuk kepentingan menyampaikan ajaranajaran Islam atau dakwah Islam. ${ }^{45}$

Dalam globalisasi dan erah informasi seperti sekarang ini, di perlukan penerapan dakwah yang dapat menjangkau tersebut.Dengan demikian dakwah harus di kembangkan melalui berbagai strategi. ${ }^{46}$

Aktivis dakwah Islam saat ini tidak cukup dengan menggunakan media-media tradisional, seperti melalui ceramah-ceramah dan pengajianpengajian yang masih menggunakan media komunikasi oral atau komunikasi tutur. penggunaan media-media komunikasi modern sesuai dengan taraf perkembangan daya pikir manusia harus dimanfaatkan sedemikian rupa, agar dakwah Islam lebih mengenah sasaran dan tidak out of date. ${ }^{47}$

\section{Materi Kajian Keislaman LDK Jundullah IAIN Palu}

Alqurān dan hadis merupakan materi kajian yang selalu menjadi patokan dalam setiap penemuan masalah kajian-kajian keIslaman. Secara umum materi dakwah dapat diklasifikasikan menjadi 3 masalah pokok, yaitu:

1. Masalah aqidah

2. Masalah keIslaman (Syariat)

3. Masalah akhlak qul karimah atau budi pekerti

Ajaran akhlak atau budi pekerti dalam Islam termasuk kedalam materi dakwah yang penting untuk di sampaikan kepada masyarakat

${ }^{45}$ Ibid., h. 113.

${ }^{46}$ Samsul Munir Amin. Ilmu Dakwah, (Cet. I; Jakarta: Sinar Grafika Offset, 2009), h. 111 .

${ }^{47}$ Ibid., h. 112. 
penerima dakwah.Islam menjunjung tinggi nilai-nilai moralitas dalam kehidupan manusia.Dengan akhlak yang baik dan keyakinan agama yang kuat maka Islam membendung terjadinya moral dekadensi. ${ }^{48}$

LDK Jundullah IAIN Palu memiliki Materi kajian liqo dan ibtor jama'i atau kajian pembinaan yang bersifat internal, materi kajiannya sudah tersusun dengan rapi di antaranya yaitu:

1. Pembentukan aqidah (Syahadattain) ${ }^{49}$

2. Masalah keislaman (syariat $)^{50}$

LDK memiliki slogan "Berpelangi Dengan Cinta" jadi meskipun mereka berbeda tetapi mereka di satukan dalam dakwah.

\section{Niat}

Ustaz Andi Karman mengatakan bahwa:

"tiap-tiap urusan itu sesuai dengan apa yang di niatkan dan syarat agar amal kita di terima oleh allah Swt itu tergantung dari niat yang berasal dari hati dan di ucapkan melalui lisan sebagai penguatan. Rusaknya amalan-amalan itu tergantung dari niat, niat juga dapat membedakan amalan-amalan ibadah baik itu yang bersifat wajib,sunnah maupun mubah, kemudian tiap-tiap amalan harus di sertai dengan niat". ${ }^{51}$

\section{Thaharah}

5. Kepribadian Islam

6. Indahnya kasih sayang Rasulullah Saw. ${ }^{52}$

${ }^{48}$ Ibid, h. 92

${ }^{49}$ Kaharuddin Ketua LDK Jundullah IAIN Palu. Wawancara. Di Sekretariat LDK Jundullah IAIN Palu pada tanggal 02 juli.

${ }^{50}$ Mardatillah. Wawancara, di kampus IAIN Palu pada tanggal 03 juli 2016.

${ }^{51}$ Ustat Andi Karman, Kajian Ibtor Jama'i. Di Masjid IAIN Palu pada tanggal 17 April 2016.

${ }^{52}$ Mardatillah, kajian Kemuslimahan. Di taman rektorat IAIN Palu pada tanggal 28 April 2016 
Mariam, Syamsuri, Adam, Transformasi Kajian Keislaman....

7. Pemahaman terhadap siyasa (politik)

8. Akhlak $^{53}$

9. Mujahidin binapsi (mengendalikan hawa nafsu)

10. Kemampuan mencari kehidupan

11. Teratur dalam urusan

12. Disiplin waktu dan

13. Iqra' ${ }^{54}$

14. Bermanfaat bagi orang lain. ${ }^{55}$

Akan tetapi ada juga kajiannya yang tidak tersusun, yaitu kajian untuk umum materinya sesuai dengan problema yang ada di masyarakat contohnya ketika mengadakan seminar-seminar temanya sesuai dengan problema yang ada di masyarakat, adapun seminar yang pernah di laksanakan selama jabatan Kaharuddin sebagai ketua LDK Jundullah IAIN Palu periode 2015- 2016 yaitu:

1. Muhasabah Cinta

2. Metode Cepat Membaca Alqurān

3. Aliran Islam modern dalam sorotan Ahlul Sunnah Wal Jamaah, dengan tujuan untuk mencerdaskan mahasiswa dan masyarakat memahamkan tentang bagaimana aliran-aliran Islam yang baru itu sebenarnya sehingga mahasiswa dan masyarakat tidak mudah terpengaruh dengan aliran-aliran yang baru seperti syiah dan jaringan Islam liberal (JIL). ${ }^{56}$

${ }^{53}$ Kaharuddin, Wawancara. Di secret LDK Jundullah IAIN Palu pada Tangal 02 Juni 2016.

${ }^{54}$ Dr. Adam Saleh, M.Pd, M.Si, Kajian Ibtor. Di Masjid Kampus IAIN Palu pada Tanggal 04 Mei 2016.

${ }^{55}$ Nur Hikmah, wawancara .Di secret LDK Jundullah IAIN Palu pada Tangal 02 Juni 2016.

${ }^{56}$ Kahar ketua LDK IAIN Palu, Wawancara.Di secret LDK IAIN pada tanggal 02 juli 2016. 


\section{Pengamalan Ajaran KeIslaman LDK Jundullah IAIN Palu}

Pada dasarnya seorang juru dakwah hendaklah memiliki kemampuan komprehensif di dalam masalah-masalah agama Islam, di samping itu sekaligus mengamalkannya. Sehingga dengan demikian, kunci sukses seorang dai terletak pada kesungguhan dan keikhlasan dalam menyampaikan ajaran-ajaran Islam. ${ }^{57}$

Fadli Rais mengemukakan bahwa amalan-amalan keIslaman LDK Jundullah IAIN Palu yaitu:

"Adapun pengamalan ajaran keIslaman Lembaga Dakwah Kampus Lebih mengedepankan akhlak dan keteladanan di kampus,sebenarnya dalam melaksanakan amal-amalan Islam harus keseluruhan akan tetapi masih banyak kader-kader yang baru bergabung di LDK jundullah maka mereka anggota LDK menyesuaikan karena anggota baru masih perlu banyak belajar mengenai amalan Islam dan pelaksanaannya pun masih bertahap, berjenjang atau berlevel.

Dalam kode etik LDK sebenarnya kader LDK diwajibkan untuk melatih diri dalam melaksanakan amalan-amalan Islam misalnya satu minggu satu kali sholat malam,puasa senin kamis,baca $A l-$ qur'an satu hari satu Juz, dan membaca buku satu hari minimal 25 halaman itulah sering di tekankan kepada kader karena menurut Imam Hasan Al-bana bahwa salah satu faktor yang menyebabkan bangkitnya umat Islam atau dakwah adalah dari fikriyah dan ruhiyah atau kedekatannya dengan Allah SWT sedangkan fikriyah adalah kapasitas ilmu pengetahuannya misalnya jika kader LDK punya kapasitas fikriyah yang bagus namun dari segi ruhiyyah tidak bagus maka itu tidak akan mendatangkan keberkahan karena ruhiyyanya tidak bagus tidak ada kedekatan dengan Allah SWT artinya hatinya gersang,sebaliknya ruhiyyah bagus tetapi kapasitas keilmuannya kurang maka kurang baik,karena bagaimana kita harus berdakwah sedangkan ilmu kita tidak mempuni. ${ }^{, 58}$

\footnotetext{
${ }^{57}$ Fadli Rais, Wawancara.Di sekret LDK Jundullah IAIN Palu. pada tanggal 03 juli 2016

${ }^{57}$ Ibid., h. 29
} 
Mariam, Syamsuri, Adam, Transformasi Kajian Keislaman....

Dengan demikian menjadi seorang dai harus mengkonsentrasikan dirinya dalam tugas menggali ilmu dan ajaran agama Islam untuk di sampaikan kepada orang lain sehingga ilmu dan ajaran agamanya dapat mempengaruhi sikap dan tingkalaku orang tersebut.

Berdakwah adalah usaha manusia untuk menyeruh/mengajak manusia dengan ajaran Islam agar menerima, meyakini, dan mengamalkan ajaran Islam bahkan memperjuangkannya. Dengan demikian, maka yang menjadi objek telaah ilmu dakwah adalah dengan segala sikap tingkah lakunya yang berkaitan dengan aktivitas dakwah. ${ }^{59}$

1. Faktor Pendukung

LDK Jundullah IAIN Palu ini memiliki sejarah yang sangat panjang, mulai dari pertama di bentuknya pada tahun 2002, organisasi ini melakukan berbagai hal dan melahirkan kader-kader yang kemudian hari menjadi tokoh-tokoh di bangsa ini.

Faktor pendukung organisasi LDK Jundullah IAIN Palu yaitu memiliki jaringan yang luas, karena LDK memiliki Pusat komunikasi LDK di berbagai daerah sehinnga dapat mendukung proses pengkaderan dan penyebaran misi Organisasi LDK Jundullah IAIN Palu.

Memiliki kader-kader yang kapasitas keilmuannya luas, sehingga dapat membantu menjalankan proses dakwah dengan cara yang lebih tepat dan mampu melahirkan karya-karya yang patut di banggakan contohnya mantan ketua LDK Jundullah IAIN Palu periode 2014-2015 Muamar Zuhdi Ar-Salan beliau berhasil me-louncing sebuah buku dengan judul "satu menit yang mengubah". 
Kemudian memiliki sumber daya kader yang di miliki LDK, dalam menghidupkan organisasinya maupun dalam menjalankan misi dakwahnya. Sumber daya kader ini pulalah yang selalu berperan dalam setiap aktivitas LDK termasuk dalam membentuk jaringan. Kader menjadi orang terpenting di setiap keberadaannya sehingga dapat menbentuk dan menjalin jaringan-jaringan baru yang dapat membantu proses tercapainya misi LDK.

Sekretariat adalah faktor terpenting selanjutnya dalam memnentukan hidup matinya suatu organisasi termasuk pada organisasi LDK.Sekretariat merupakan pusat gerakan, pusat komunikasi, dan pusat segala aktivitas organisasi.

Fadli Rais mengemukakan bahwa faktor pendukung dalam mengakses informasi keIslaman yang di laksanakan oleh LDK Jundullah IAIN Palu yaitu dana,dukungan dosen atau birokrasi, dan semangat teman-teman kader LDK. ${ }^{60}$

2. Faktor Penghambat

Selain faktor pendukung dalam proses mengakses informasi keIslaman LDK Jundullah IAIN Palu juga tidak luput dari faktor penghambat, antara lain; pertama, berkaitan dengan dana, bahwa LDK tidak memiliki asupan dana yang paten anggotapun tidak diberi beban membayar iuran sehingga organisasi selalu mengalami kekurangan dana. Kedua adanya kader-kader yang sudah tidak aktif di organisasi Lembaga Dakwah Kampus karena banyaknya tugas kampus dan selain berorganisasi sebagian kader LDK Jundullah IAIN Palu tidak hanya memiliki aktifitas kuliah dan berorganisasi saja tetapi di samping itu

${ }^{60}$ Zul Fadli Rais, Wawancara. Di secret LDK Jundullah IAIN Palu,tanggal 09 juli 
Mariam, Syamsuri, Adam, Transformasi Kajian Keislaman....

mereka juga bekerja sehingga tidak banyak yang membantu dalam mengakses informasi keIslaman." ${ }^{\circ 1}$ Meski demikian LDK juga akan melakukan pembinaan yang lebih instens agar menghasilkan kader-kader yang lebih konsisten dalam berorganisasi.

\section{Kesimpulan}

Organisasi LDK IAIN Palu sangat memperhatikan kajian keIslaman sehingga dapat secara optimal mencapai tujuan agar mahasiswa dan masyarakat khususnya yang beragama Islam mampu memahami Islam sebagai agama yang dapat membentuk akhlaq yang lebih baik. Disamping itu kajian kelslaman dapat memberikan alternatif lain yang mampu menghilangkan rasa jenuh masyarakat akibat datangnya aliranaliranbaru Islam yang sangat bertolak belakang dengan Alqurān dan AsSunnah.

Dalam mewujudkan transformasi kajian keislaman LDK Jundullah menjalankan perannya sebagai media dakwah organisasi LDK IAIN Palu melakukan beberapa hal yaitu: menyelenggarakan seminar-seminar kemudian membuat pelatihan dai-daiyah, mengontrol kader dan membuat program liqo tiap minggu, kemudian ada daura aktifis dakwah kampus satu itu gerbang masuk LDK dan daura aktifis kampus dua adalah jenjang pendidikan LDK.

Departemen kemuslimahan ini khusus untuk muslimah yaitu mengadakan daura maratusaliha, seminar kemuslimahan, seminar inspiratif, kajian-kajian kemuslimahan. Bidang pemberdayaan ekonomi

${ }^{61}$ Zul Fadli Rais, Wawancara. Di sekretariat LDK IAIN Palu tanggal 02 Juli 2016. 
melakukan pelatihan kepada para kader LDK dalam berniaga atau berwirausaha.

Melakukan pengamatan terhadap situasi dan kondisi yang di hadapi oleh mahasiswa dan masyarakat maka Organisasi LDK IAIN Palu dalam menyampaikan kajian-kajian kelslaman dengan mengikuti perkembangan zaman.

Adapun amalan-amalan yang di laukan oleh LDK Jundullah IAIN mengedepankan akhlak dan keteladanan di kampus, sebenarnya dalam melaksanakan amal-amalan Islam harus keseluruhan akan tetapi masih banyak kader-kader yang baru bergabung di LDK Jundullah maka mereka anggota LDK menyesuaikan karena anggota baru masih perlu banyak belajar mengenai amalan Islam dan pelaksanaannya pun masih bertahap, berjenjang atau berlevel.

\section{Daftar Pustaka}

Abdullah, Dzikron, Metodologi Da'wah, Semarang: Fakultas Dakwah IAIN Walisongo, 1987.

Abdullah, Rahmat. Dakwah Masyarakat Fokus Dakwah Di Era Baru. Cet.I; Jakarta: Penerbit Izzah Press, 2001.

Al-Albani, Nasiruddin, Ringkasan Shahih Bukhari. Cet. I; Jakarta: Gema Insani, 2003.

Amin, Samsul Munir, Ilmu Dakwah, Jakarta: Amzah, 2009.

Anshory, Isa, Mujahid Dakwah, Pembimbing Mubaligh Islam, Cet V, Bandung: Di Ponegoro, 1995.

Arifin, Psikologi Dakwah Suatu Pengantar Studi. Bumi Aksara.

Arsip dokumen Lembaga Dakwah Kampus Jundullah IAIN Palu.

Aziz, Moh. Ali, Ilmu Dakwah, Edisi Revisi, Cet Ke-II Kencana, 2009 Jakarta. 
Mariam, Syamsuri, Adam, Transformasi Kajian Keislaman....

Departemen Agama RI, Al-Jumatul 'Ali Alqurān dan Terjemahnya Bandung: CV Penerbit J-Art, 2014.

Departemen Pendidikan Dan Kebudayaan, kamus Besar Bahasa Indonesia, Balai Pustaka.

Dimas. Risalah Manajemen Dakwah Kampus, Bandung: Gamais Press, 2007.

Jumantoro, Totok, Psikologi Dakwah dengan Aspek-aspek Kejiwaan yang Qur'ani. Amzah, Jakarta, 2001.

Kementerian Agama RI, Alqurān dan Terjemahnya, Bandung: Fokus Media, 2010.

Mahfudh, Sahal, Nuansa Fiqih Sosial, Cet I, Yogyakarta: LKIS, 1994

Syukir, Asmud, Dasar-dasar Strategi Dakwah Islam, Surabaya, Al-Ikhlas, 1983.

Winandi, J. Teori Organisasi Dan Pengorganisasian, Jakarta: PT. Raja Grafindo Persada, 2006.

Wahyudin, Pergerakan Dakwah Kampus di Indonesia, Cet. 1; Yogyakarta: Al-Amin Press, 1992.

Yafie, Ali, Teologi Sosial telaah Kritis persoalan agama dan kemanusiaan, Yogyakarta: LKPSM, 1997.

Ya'qub, Hamzah, Publistik Islam, Tekhnik Da'wah dan Leadership, Cet II, Bandung: CV. Diponegoro, 1981.

http://yopiekristiyanto.blogspot.com/2013/02/diklat-kader-dakwah kepemimpinan. Html. Diakses tanggal 01 mei 2016 jam 10.00 am.

http:/adhiecupu91.blogspot.com/2014/11/fenomena dakwah kampus.htm\#pages/2 .diakses pada 15 mei 2016 jam 10 AM.

http:/muslimahpejuang. wordpress.com/2011/01/10/ problematika dakwah kampus dan solusinya. Di akses pada 10 mei 2016 jam 9 AM. 